\title{
From milk to cheese: Evolution of flavor fingerprint of milk, cream, curd, whey, ricotta, scotta, and ripened cheese obtained during summer Alpine pasture
}

\author{
M. Bergamaschi ${ }^{1}$ and G. Bittante \\ Department of Agronomy, Food, Natural Resources, Animals and Environment (DAFNAE), University of Padova, 35020 Legnaro (PD), Italy
}

\begin{abstract}
The role of each step of cheese and ricotta making in development of flavor of cheese and other dairy products is not yet well known. The objectives of this study were to characterize volatile organic compounds (VOC) in cheese and ricotta making with bulk milk from cows grazing in a highland area and to evaluate their evolution in the various dairy products and byproducts obtained during the production processes. A group of 148 cows was grazed day and night on pasture from June to September. A total of 7 cheese-making sessions were carried out using the bulk milk collected every 2 wk during summer pasturing according to the artisanal procedure used for Malga cheese production. All milks, products, and by-products were sampled, and the VOC content of milk, cream, whey, ricotta, scotta (residual liquid), fresh cheeses, and cheeses ripened for 6 and 12 mo was determined by solid-phase microextraction gas chromatography-mass spectrometry. Forty-nine compounds were identified belonging to the following chemical families: alcohols (13), aldehydes (9), esters (8), free fatty acids (6), ketones (5), lactones (2), sulfurs (2), terpenes (2), phenol (1), and benzene (1). The results showed that the amounts of VOC in the various dairy products differed significantly. Comparisons between the VOC of 4 types of milk (whole evening, skim evening, whole morning, mixed in the vat) showed that the skimming process had the greatest effect, with about half of all the VOC analyzed affected, followed by time of milking (evening milking vs. morning milking) and mixing (skim evening milk mixed with whole morning milk). In general, among fresh products, cream had higher contents of fatty acids, sulfurs, and terpene volatile compounds than fresh cheese and ricotta, whereas ricotta showed a very high VOC amount compared with fresh cheese, probably due to its high processing temperature. The effects of
\end{abstract}

Received July 26, 2017.

Accepted December 22, 2017.

${ }^{1}$ Corresponding author: matteo.bergamaschi@unipd.it the progressive nutrient depletion in milk during processing were investigated by comparing the amounts of VOC in vat milk, whey, and scotta. Although milk contained greater amounts of nutrients, whey and especially scotta had higher concentrations of VOC, with the exception of esters, sulfurs, terpenes, and phenolic compounds, as a result of physicochemical and microbial modifications during processing. Finally, the effect of ripening was tested by comparing the VOC of fresh and ripened cheeses (6 and $12 \mathrm{mo}$ ), revealing that VOC release increased dramatically during the first semester and further with increasing the ripening period to 1 yr. In particular, some alcohols (butan2-ol), aldehydes (2-methylpropanal, hexanal, and heptanal), esters (ethyl butanoate and ethyl hexanoate), fatty acids (acetic, butanoic, and hexanoic acids), and ketones (butan-2-one, pentan-2-one, and heptan-2-one) showed a very large increase. In conclusion, according to the artisanal milk processing carried out for Malga cheese production, the quantity of VOC was shown to increase about 3 times during cheese making (from milk in vat to fresh cheese plus whey), almost 4 times during ricotta making (from whey to ricotta plus scotta), and about 16 times during $1 \mathrm{yr}$ of ripening of cheese.

Key words: dairy cow, dairy product, volatile organic compound, solid-phase microextraction gas chromatography-mass spectrometry

\section{INTRODUCTION}

Volatile organic compounds (VOC) are descriptors of the sensory qualities of food, including flavor (Badings, 1991; Liaw et al., 2011), and different mass spectrometric techniques can be used to detect them. For example, GC-MS can be used for qualitative and quantitative determination of the molecules responsible for flavor (Tunick, 2014).

Several studies have been published on the effects of animal diet, types of grass, and the botanical composition of pastures on VOC and the sensory properties of cheese (Agabriel et al., 2004; Carpino et al., 2004; Bovolenta et al., 2014). Milk from cows grazing on pas- 
ture contains a series of odor-active compounds that may be responsible for the specific odor of pasture milk and cheese (Carpino et al., 2004; Cornu et al., 2009). Differences in the sensory traits of cheeses depending on whether the milk has come from animals grazed on highland pastures or on lowland pastures have been reported (Martin et al., 2005; Coppa et al., 2011). The type of dairy system is therefore highly related to the final dairy product - that is, milk and cheese (Capuano et al., 2015; Giaccone et al., 2016). Recent studies have focused on quantifying the effects on cheese VOC of different dairy systems, individual animal characteristics, farm altitude, and quantity of concentrate in the diet (Bovolenta et al., 2014; Bergamaschi et al., 2015a, b).

There are few published studies on the volatile profiles of cream and ricotta and the by-products of cheese making (e.g., whey and scotta, or residual liquid). Moreover, no study thus far has focused on the flux and changes in individual VOC during the entire cheese- and ricotta-making process.

The aim of this work, which is part of the Cowplus project, was to carry out, with a holistic approach to the entire process of cheese and ricotta making, research on the development of the flavor fingerprint of cheese, following the single steps from milk to the final products (i.e., fresh and ripened cheese, cream, and ricotta) and by-products. More precisely, the objectives of our study were to investigate (1) the effect on milk VOC of skimming (whole milk vs. skim milk), time of milking (evening milk vs. morning milk), and mixing in the vat; (2) the volatile fingerprint of the fresh products (cream, curd, ricotta); (3) the volatile fingerprints of liquid fractions (vat milk, whey, and scotta); (4) the volatile fingerprint during cheese ripening; and (5) the flux of VOC during the overall cheese- and ricotta-making process (from milk to cream, ricotta, and ripened cheese).

\section{MATERIALS AND METHODS}

\section{Pasture and Animals}

The study is part of a more complex research study on traditional cheese making in the highland summer pasture involving the characterization of the processing steps, the technological properties of milk, and the recovery of nutrients in the products (Bergamaschi et al., 2016) as well as the detailed fatty acid profile of milk, products, and by-products (Bergamaschi and Bittante, 2017). It was carried out from June to September at a temporary Alpine summer farm (Malga Juribello, Paneveggio, Pale di San Martino Nature Park, Trento, Italy; $1,860 \mathrm{~m}$ above sea level) equipped for processing milk to produce traditional Malga (summer Alpine pasture) cheese. A description of the role of summer transhumance to Alpine pastures of northeast Italy is reported by Sturaro et al. (2013a, b), its effects on cows and milk technological properties are reported by Zendri et al. (2016, 2017), and details on climate conditions and quantity and quality of pasture are reported in Bergamaschi et al. (2016). A total of 148 cows of different genetic types (Brown Swiss, Holstein Friesian, Simmental, Rendena) were grazed on Alpine pasture day and night. The feeding strategy was pasture based supplemented with a compound feed given twice daily during milking in quantities according to milk production $(5.0 \pm 1.5 \mathrm{~kg} / \mathrm{d})$. The compound feed was a mixture of corn, wheat bran, soybean meal, and sugarcane molasses. As discussed in detail by Bergamaschi et al. (2016), the production traits of the cows were as follows: milk yield $=23.6 \pm 5.7 \mathrm{~kg} / \mathrm{d}, \mathrm{DIM}=233 \pm 90 \mathrm{~d}$; parity $=2.4 \pm 1.7$. The cows were milked twice daily.

\section{Cheese and Ricotta Making}

A total of 7 cheese-making sessions were carried out using the bulk milk collected every 2 wk during summer pasturing. Cheeses and ricotta were manufactured at Malga Juribello according to the procedure described in detail by Bergamaschi et al. (2016). Briefly, $250 \mathrm{~L}$ of raw whole milk from the evening milking was collected in an open flat tank to permit overnight natural creaming. The following morning, the cream on the surface was separated from the milk, and the skim milk was transferred to a vat and mixed with $250 \mathrm{~L}$ of freshly collected morning whole milk. The milk in the vat was heated $\left(27^{\circ} \mathrm{C}\right)$; inoculated with $250 \mathrm{~g}$ of full-fat yogurt made of pasteurized milk, Streptococcus thermophilus, and Lactobacillus bulgaricus (Latte Trento, Trento, Italy); and rennetted with $25 \mathrm{~g}$ of commercial rennet (Naturen extra 1030 NB, 1,030 international milk clotting units/g; Chr. Hansen A/S, Hørsholm, Denmark). The resulting curd was cut, turned to facilitate draining, and cooked at $45^{\circ} \mathrm{C}$ for $15 \mathrm{~min}$. After cooking, the curd was put into molds $(30 \mathrm{~cm}$ diameter $\times 12 \mathrm{~cm}$ high), pressed, salted in brine for $80 \mathrm{~h}$, and ripened in a cellar at $12^{\circ} \mathrm{C}$ with a relative humidity of $85 \%$ for 6 or 12 mo. In addition, during the cheese-making session the whey was transferred to a smaller vat and heated to $90^{\circ} \mathrm{C}$; then, $0.750 \mathrm{~L}$ of vinegar was added to catalyze the coagulation. The resulting ricotta was separated, weighed, and placed into molds $(20 \mathrm{~cm}$ diameter $\times 15$ $\mathrm{cm}$ high) to allow the scotta to drain.

\section{Sampling}

A total of 11 dairy products were collected from each of the 7 cheese-making sessions. These were 4 types 
of raw milk (whole evening milk, skim evening milk, whole morning milk, and vat milk - a mixture of skim and whole morning milk), 3 fresh products (cream, fresh cheese, and ricotta), 2 liquid by-products (whey and scotta), and 2 ripened cheeses (6 and $12 \mathrm{mo}$ ). All samples were stored at $-20^{\circ} \mathrm{C}$ until analysis.

\section{Laboratory Analysis}

Quality Traits. The chemical traits of milk, cream, whey, ricotta, scotta, curd, and cheese were analyzed at the Department of Agronomy, Food, Natural Resources, Animals and Environment (University of Padova, Legnaro, Padova, Italy) and are reported in Table 1. Fat, protein, and lactose percentages were determined using a MilkoScan FT2 apparatus (Foss Electric A/S, Hillerød, Denmark), and the chemical compositions of the fresh cheese (curd), ricotta, and ripened cheeses (6 and $12 \mathrm{mo}$ ) were measured with a FoodScan (Foss Electric A/S).

VOC. Volatile organic compounds were analyzed by solid-phase microextraction (SPME) GC-MS at the Food Quality and Nutrition Department of Fondazione Edmund Mach (San Michele all'Adige, Trento, Italy). Volatile organic compounds were extracted by means of a modified version of the procedure described by Bovolenta et al. (2014). Briefly, 3-g samples of each of the 11 products (evening whole milk, skim milk, morning whole milk, vat milk, cream, fresh cheese, ricotta, whey, scotta, and 6 mo- and 12 mo-ripened cheese) from each cheese-making session were placed in glass vials (20 mL; Supelco, Bellefonte, PA), to which was added $2 \mathrm{~g}$ of sodium chloride (Aldrich, Milan, Italy), 4 $\mathrm{mL}$ of bidistilled water, $50 \mu \mathrm{L}$ of a solution of 3 internal standards with purity not lower than 99\% (4-methylpentan-2-one $=0.0049 \mathrm{mg} / \mathrm{mL}$, Aldrich; ethyl heptanoate $=0.0049 \mathrm{mg} / \mathrm{mL}$, Aldrich; and isobutanoic acid $=1.999 \mathrm{mg} / \mathrm{mL}$, Fluka, Milan, Italy), and a magnetic stir bar before capping with polytetrafluoroethylene/ silicone septa (Supelco). Each sample was measured in triplicate. Volatile compounds were concentrated on the SPME fiber (50/30 $\mu \mathrm{m}$ of divinylbenzene/carboxen/polydimethylsiloxane, Supelco). After extraction, samples were desorbed for $5 \mathrm{~min}$ in the GC injector at $250^{\circ} \mathrm{C}$ interfaced to a mass detector operating in electron ionization mode (internal ionization source; $70 \mathrm{eV}$ ) with a scan range of 30 to $300 \mathrm{~m} / z$ (mass:charge ratio; GC Clarus 500, PerkinElmer, Norwalk, CT). Samples were injected using an autosampler (CTC combiPAL, CTC Analysis AG, Zwingen, Switzerland). Separation was then achieved on an HP-Innowax fused-silica capillary column (30 m long, $0.32 \mathrm{~mm}$ internal diameter, $0.5 \mu \mathrm{m}$ film thickness; Agilent Technologies, Palo Alto, CA). The oven temperature program was as follows: initial temperature of $40^{\circ} \mathrm{C}$ held for $3 \mathrm{~min}$, increased to $180^{\circ} \mathrm{C}$ at $4^{\circ} \mathrm{C} / \mathrm{min}$ and then held for $6 \mathrm{~min}$, and increased to $220^{\circ} \mathrm{C}$ at $5^{\circ} \mathrm{C} / \mathrm{min}$. Carrier gas was helium with a constant column flow rate of $2 \mathrm{~mL} / \mathrm{min}$. The compounds were identified by comparing their mass spectra with the standard Wiley and NIST MS library (McLafferty, 2006) and by comparing their retention times with those described in the literature. The chromatograms obtained from the total ion current were integrated. Results were expressed as micrograms per kilogram equivalent to the internal standard (4-methylpentan-2-one) to compare the different chemical classes of compounds in terms of relative quantity within each dairy product. In addition, 2 replicates of a reference

Table 1. Descriptive statistics of chemical composition of sampled dairy products $(\mathrm{n}=7)$ during summer transhumance

\begin{tabular}{|c|c|c|c|c|c|c|}
\hline \multirow[b]{2}{*}{ Dairy product } & \multicolumn{2}{|c|}{ Fat $(\%)$} & \multicolumn{2}{|c|}{ Protein (\%) } & \multicolumn{2}{|c|}{ Lactose $(\%)$} \\
\hline & Mean & $\mathrm{SD}$ & Mean & $\mathrm{SD}$ & Mean & $\mathrm{SD}$ \\
\hline \multicolumn{7}{|l|}{ Processed fluids } \\
\hline Evening whole milk & 4.08 & 0.53 & 3.68 & 0.09 & 4.79 & 0.12 \\
\hline Evening skim milk & 2.53 & 0.29 & 3.72 & 0.08 & 4.94 & 0.12 \\
\hline Morning whole milk & 4.31 & 0.70 & 3.68 & 0.08 & 4.86 & 0.10 \\
\hline Milk in vat $(\operatorname{mix})^{1}$ & 3.37 & 0.25 & 3.70 & 0.09 & 4.89 & 0.13 \\
\hline Whey & 0.59 & 0.09 & 0.95 & 0.07 & 4.79 & 0.31 \\
\hline Scotta $^{2}$ & 0.01 & 0.01 & 0.56 & 0.03 & 5.05 & 0.23 \\
\hline \multicolumn{7}{|l|}{ Fresh products } \\
\hline Cream & 28.1 & 2.97 & 3.22 & 0.22 & 3.43 & 0.13 \\
\hline Fresh cheese & 20.4 & 0.69 & 20.2 & 0.93 & - & - \\
\hline Ricotta & 8.85 & 1.86 & 8.79 & 1.21 & - & - \\
\hline \multicolumn{7}{|l|}{ Ripened cheese } \\
\hline Cheese $(6 \mathrm{mo})$ & 29.4 & 0.55 & 29.9 & 0.76 & - & - \\
\hline Cheese (12 mo) & 30.1 & 0.78 & 32.2 & 0.89 & - & - \\
\hline
\end{tabular}

${ }^{1}$ Obtained by mixing the evening skim milk with the morning whole milk in equal parts.

${ }^{2} \mathrm{Scotta}=$ residual liquid after ricotta separation. 
sample prepared by homogenizing cheese from the trial were analyzed on each of the $19 \mathrm{~d}$ of analysis to evaluate instrumental repeatability. Averaged variations in the alcohol, ester, ketone, acid, and aldehyde families were $18.1,23.1,18.4,33.0$, and $15.2 \%$, respectively. These repeatability results were consistent with the literature on SPME analysis (Bovolenta et al., 2014; Bergamaschi et al., 2015a).

\section{Statistical Analysis}

The data were transformed to $\ln (\mathrm{x}+1)$ to obtain Gaussian-like data distribution before any data treatment. After transformation, VOC data from the 11 dairy products obtained from each cheese-making session were processed using PROC MIXED (SAS Institute Inc., Cary, NC) according to the following statistical model:

$$
\mathrm{Y}_{\mathrm{ijk}}=\mu+\text { dairy product }_{\mathrm{i}}+\text { date }_{\mathrm{j}}+\mathrm{e}_{\mathrm{ijk}} \text {, }
$$

where $y_{\mathrm{ijk}}$ is the VOC contents, their chemical family, and sum; $\mu$ is the overall mean; dairy product $t_{i}$ is the fixed effect of the ith dairy product $(\mathrm{i}=1-11)$; date $_{\mathrm{j}}$ is the repeated effect of the jth cheese-making session $(\mathrm{j}=1-7)$; and $\mathrm{e}_{\mathrm{ijk}}$ is the residual random error term $\sim N\left(0, \sigma^{2}\right)$, where $\sigma^{2}$ is the residual variance. In addition, orthogonal contrasts were used to investigate the effects of milk treatment (time of milking, skimming, mixing), differences among the fresh products, milk nutrient depletion, and cheese ripening period.

\section{RESULTS AND DISCUSSION}

\section{VOC}

A total of 49 compounds were detected by SPME/ GC-MS in at least 1 of the dairy products analyzed. These compounds belong to the following chemical classes: alcohols (13), aldehydes (9), esters (8), free fatty acids (6), ketones (5), lactones (2), sulfurs (2), terpenes (2), phenol (1), and benzene (1; Supplementary Table S1, https://doi.org/10.3168/jds.2017-13573). The main VOC identified from the headspace in terms of relative abundance (expressed as $\ln$ of $\mu \mathrm{g} / \mathrm{kg}$ ) were ethyl butanoate and ethyl hexanoate from milk and fresh cheese; hexanoic acid, ethyl butanoate, and butanoic acid from cream; hexanal, heptanal, and octanal from ricotta; hexan-1-ol and hexanal from whey; 3-methylbutan-1-ol from scotta; and butan-2-ol and butanoic acid from ripened cheeses. The differences of the VOC among the 11 dairy products were in most cases statistically significant $(P<0.05)$.
The relative abundance of VOC in the milk samples was much smaller than in the other dairy products, and fewer compounds were detected in milk: 8 of the 13 alcohols, 8 of the 9 aldehydes, 6 of the 8 esters, 5 of the 6 fatty acids, 4 of the 5 ketones, and all 8 "other" VOC. The majority of the compounds we identified were also found by Marsili (1999) and Tunick et al. (2015). Moreover, milk VOC were affected by time of milking, skimming, and mixing milk before cheese making.

\section{Effects of Time of Milking on Milk VOC}

As shown in Table 2, the 2 milkings (evening and morning) yielded milk with similar total content of VOC as well as similar quantities of different chemical classes of compounds, with the exception of the smaller relative contents of ketones in the morning milk compared with the evening milk. More than half the individual VOC (21/34) were affected by time of milking, although only in a dozen cases were the differences large. Of these, it is worth noting that there was more 8-carbon chain compounds and methylsulfonylmethane (dimethyl sulfone) in the morning whole milk and more 2-phenoxyethanol, 2-methylpropanal, butan-2-one, methylthiomethane, 6-propyloxan-2-one, and both limonene and $\alpha$-pinene in the evening whole milk.

The effect of time of milking has rarely been studied. Fat content is greater in morning milk (Table 1), and the fatty acid profile is different from that in evening milk (data not shown). Martin et al. (2009) observed that milking influenced milk composition and quality characteristics, including the volatile profile of the final product. The authors are not aware of any direct studies of the differences between morning and evening milk in relation to their VOC profiles. However, in seeking to explain the differences we found, it should be remembered that the milkings were done $12 \mathrm{~h}$ apart (0400 and $1600 \mathrm{~h})$, that the cows were outside and free to graze day and night in the same pasture area, and that the compound feed was given to individual cows during both milkings (half in the morning and half in the evening). Therefore, the differences between the VOC profiles of morning and evening milks were not due to milking intervals, although milking intervals have been found to affect LPL activity (Gobbetti et al., 1996; Chilliard et al., 2003). These differences could be due to forage quality, as the metabolic activity of the plants can vary during the day (Harmer, 2009) and consequently form different secondary metabolites. Different environmental light conditions and temperature can modify the circadian rhythms of the cows, their physiological state, foraging behavior, and productive performances (Bitman et al., 1984; Das et al., 2016). 
The effect of time of milking could also be related to the SCS $\left[\log _{2}(\mathrm{SCC} / 100,000)+3\right]$ content in morning (4.51 units) and evening (3.62 units) milk, which is sometimes accompanied by elevated levels of milk enzymes (Coulon et al., 2004), which may increase fat and protein degradation.

Table 2. Effect of natural skimming, time of milking, and mixing on volatile organic compounds (VOC) of milk expressed as natural logarithm of concentration $(\mu \mathrm{g} / \mathrm{kg})$

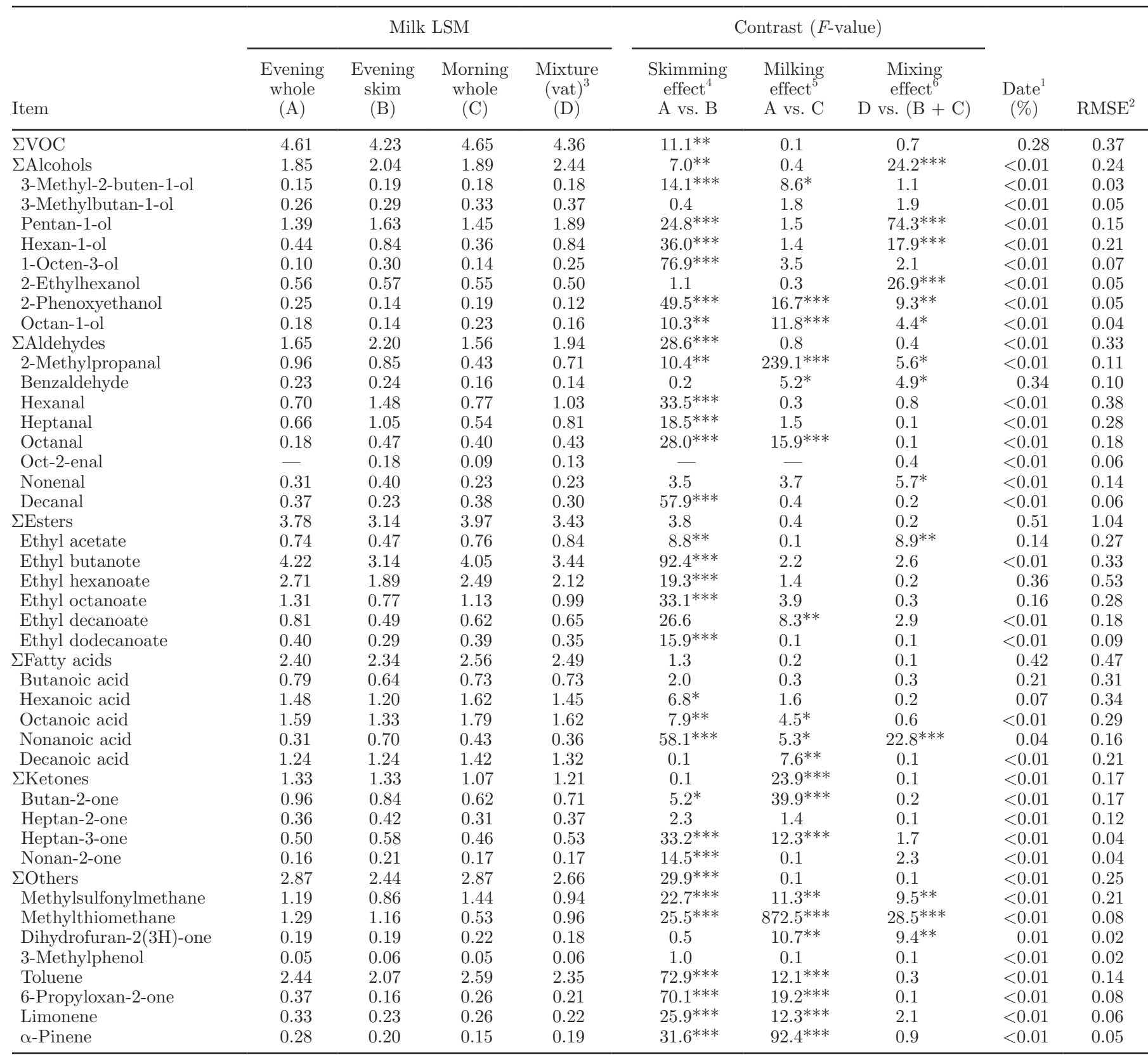

${ }^{1} P$-values of the repeated factor cheese-making date.

${ }^{2} \mathrm{RMSE}=$ root mean squared error. Concentrations are expressed in micrograms equivalent to 4-methyl-pentan-2-one.

${ }^{3}$ Obtained by mixing the evening skim milk with the morning whole milk in equal parts.

${ }^{4}$ Contrast between whole milk from the evening milking and evening skim milk.

${ }^{5}$ Contrast between whole milk from the evening milking and whole milk from the morning milking.

${ }^{6}$ Contrast between milk collected from the vat and the mean of the milk from morning milking and evening skim milk.

${ }^{*} P<0.05 .{ }^{* *} P<0.01 .{ }^{* * *} P<0.001$. 


\section{Effects of Skimming on Milk VOC}

The evening milk after overnight natural creaming had larger amounts of alcohols and aldehydes than evening whole milk and lower amounts of total VOC (Table 2). The skim milk had also smaller amounts of the most abundant classes of esters and "other" compounds, whereas fatty acids and ketones were not significantly affected.

The patterns were also different within the chemical classes. After skimming, the milk contained higher VOC derived from lactose metabolism such as 3-methyl-2-buten-1-ol or products of oxidation such as pentan-1-ol and hexan-1-ol (McSweeney and Sousa, 2000) and far more VOC derived from other metabolic pathways. For example, of the 8 aldehydes, oct-2-enal was identified only after skimming, and there was a large increase in hexanal, heptanal, and octanal and a decrease in 2-methylpropanal and decanal in the evening skim milk. Of the 5 fatty acids generally produced from lipolysis of milk fat (McSweeney and Sousa, 2000), there were fewer hexanoic and octanoic acids, whereas nonanoic acid more than doubled after natural overnight creaming. Of the 4 ketones identified, butan2-one (a product of diacetyl metabolism) decreased, whereas heptan-3-one and nonan-2-one (produced from $\beta$-oxidation and decarboxylation of free fatty acids; McSweeney and Sousa, 2000) increased. All the other VOC decreased after skimming with the exception of dihydrofuran-2(3H)-one ( $\gamma$-butyrolactone) and 3-methylphenol. The explanation for the differences between skim and whole evening milk could be related to (1) the time (overnight) taken for natural creaming and related metabolic activities in the milk (Gatti et al., 2014) or (2) the concentrations in cream during gravity separation of fat, SCC, and microorganisms present in the milk (Caplan et al., 2013).

\section{Effects of Mixing Evening Skim and Morning Whole Milk on VOC}

Overall, the total VOC content of vat milk did not differ from the expected intermediate value between the mixture of evening skim milk and whole morning milk. This was the case for all the chemical classes of VOC except the alcohols (Table 2). Of the individual VOC, the values of 14 out of 34 compounds in the vat milk were not as expected. Bearing in mind that the average value of the 2 linear concentrations does not correspond to the average of their log-transformations, it should be noted that the chromatograms of the vat milk samples showed a large increase in the relative contents of pentan-1-ol, hexan-1-ol, and ethyl acetate and a decrease in 2-ethylhexanol, 2-phenoxyethanol, and nonanoic acid. These variations have not been studied before and could be due to oxidation occurring during the time interval between sampling the 2 milks (in the creaming tank and in the milk parlor tank) and mixing them in the vat with stirring and partial oxygenation and to the increase in temperature (Barrefors et al., 1995; Timmons et al., 2001).

\section{VOC Profiles of Fresh Products (Cream, Cheese, and Ricotta)}

The relative abundances of VOC were much greater in fresh products than in milk (Table 3), and there were large differences between them. On a linear scale, the concentrations were $78 \mu \mathrm{g} / \mathrm{kg}$ in vat milk, $854 \mu \mathrm{g} / \mathrm{kg}$ in cream, $572 \mu \mathrm{g} / \mathrm{kg}$ in fresh cheese, and $2,724 \mu \mathrm{g} / \mathrm{kg}$ in ricotta. Esters and fatty acids were the 2 most abundant chemical classes in terms of relative quantity in fresh dairy products. The behavior of the esters is probably due to the parallel increase of the short- and medium-chain fatty acids during the same process. In fact, the fatty acids are synthetized by 3 different pathways - proteolysis, lipolysis, and lactose fermentation - and can be converted to other volatile compounds, including esters (McSweeney and Sousa, 2000). Butanoic acid and hexanoic acid were previously reported as odor compounds in sweet cream butter (Peterson and Reineccius, 2003), whereas the presence of esters such as ethyl acetate and ethyl butanoate was reported in fresh cheeses (Collin et al., 1993).

The VOC profiles of the fresh dairy products and of the milks were similar. The same 8 alcohols were present in both categories of dairy products, but the aldehyde 3-methylbutanal was found in an appreciable amount in cream but not in milk, fresh cheese, and ricotta. Ethyl lactate appeared only in the ricotta samples, acetic acid appeared only in cream and ricotta samples, and pentan-2-one was found only in ricotta samples.

The relative quantities of VOC of the various chemical classes in cream were roughly intermediate between the other 2 dairy products, with the notable exception of the VFA except acetic acid, which were present in greater quantities in the cream samples (Table 3). In the case of aldehydes, 3-methylbutanal (a product of the leucine degradation; Curioni and Bosset, 2002) was identified in cream but not in the other 2 dairy products, whereas oct-2-enal was not found (but was found in the other products). Numerous aldehydes (e.g., 3-methylbutanal, hexanal, nonanal) have been identified in dairy products produced by cream (e.g., butter; Peterson and Reineccius, 2003). All the others classes were found in greater concentrations in cream than in fresh cheese and ricotta with the exception of 
dihydrofuran-2(3H)-one ( $\gamma$-butyrolactone) that could be formed from hydroxyl acid from triglycerides on heating (Fox et al., 2004).

The VOC profile of ricotta was very different from that of fresh cheese (Table 3). Some alcohols (particu- larly 3-methylbutan-1-ol, hexan-1-ol, and 1-octen-3-ol) and their sum were much greater in ricotta, but 2-ethylhexanol was found in smaller amounts. The relative content of volatile aldehydes (expressed in $\mu \mathrm{g} / \mathrm{kg}$ ) was about 150 times greater in ricotta than in fresh

Table 3. Comparison of volatile organic compounds (VOC) of fresh products obtained during cheese and ricotta making expressed as natural logarithm of concentration $(\mu \mathrm{g} / \mathrm{kg})$

\begin{tabular}{|c|c|c|c|c|c|c|c|}
\hline \multirow[b]{2}{*}{ Item } & \multicolumn{3}{|c|}{ LSM } & \multicolumn{2}{|c|}{ Contrast ( $F$-value) } & \multirow[b]{2}{*}{$\begin{array}{c}\text { Date }^{1} \\
(\%)\end{array}$} & \multirow[b]{2}{*}{$\mathrm{RMSE}^{2}$} \\
\hline & $\begin{array}{l}\text { Cream } \\
\text { (A) }\end{array}$ & $\begin{array}{c}\text { Fresh cheese } \\
\text { (B) }\end{array}$ & $\begin{array}{l}\text { Ricotta } \\
\quad(\mathrm{C})\end{array}$ & $\begin{array}{c}\text { A vs. } \\
(B+C)\end{array}$ & B vs. C & & \\
\hline$\overline{\mathrm{VVOC}}$ & 6.75 & 6.35 & 7.91 & $47.5^{* * *}$ & $50.3^{* * *}$ & 0.01 & 0.53 \\
\hline ¿Alcohols & 3.50 & 3.50 & 4.90 & $46.4^{* * *}$ & $141.6^{* * *}$ & 0.18 & 0.38 \\
\hline 3-Methyl-2-buten-1-ol & 0.56 & 0.40 & 0.45 & $19.7^{* * *}$ & 2.1 & 0.07 & 0.11 \\
\hline 3-Methylbutan-1-ol & 2.14 & 1.65 & 4.29 & $40.9^{* * *}$ & $335.3^{* * *}$ & $<0.01$ & 0.44 \\
\hline Pentan-1-ol & 2.77 & 2.52 & 3.10 & 0.1 & $23.9^{* * *}$ & 0.03 & 0.38 \\
\hline Hexan-1-ol & 1.30 & 2.49 & 3.14 & $106.8^{* * *}$ & $14.3^{* * *}$ & $<0.01$ & 0.55 \\
\hline 1-Octen-3-ol & 0.61 & 0.55 & 2.65 & $201.3^{* * *}$ & $671.1^{* * *}$ & 0.02 & 0.26 \\
\hline 2-Ethylhexanol & 1.34 & 1.45 & 0.82 & $25.1^{* * *}$ & $174.7^{* * *}$ & $<0.01$ & 0.15 \\
\hline 2-Phenoxyethanol & 0.71 & 0.16 & 0.57 & $39.7 * * *$ & $37.9^{* * *}$ & $<0.01$ & 0.20 \\
\hline Octan-1-ol & 0.78 & 0.38 & 0.86 & $14.1^{* * *}$ & $97.6^{* * *}$ & $<0.01$ & 0.15 \\
\hline ¿Aldehydes & 3.39 & 2.74 & 7.75 & $251.3^{* * *}$ & $1,366.8^{* * *}$ & 0.02 & 0.44 \\
\hline 2-Methylpropanal & 1.72 & 0.73 & 3.84 & $33.8^{* * *}$ & $748.9^{* * *}$ & $<0.01$ & 0.36 \\
\hline 3-Methylbutanal & 2.50 & - & - & - & - & - & 0.15 \\
\hline Benzaldehyde & 0.70 & 1.19 & 2.62 & $164.7^{* * *}$ & $156.5^{* * *}$ & $<0.01$ & 0.33 \\
\hline Hexanal & 1.04 & 1.76 & 7.45 & $846.2^{* * *}$ & $1,498.6^{* * *}$ & $<0.01$ & 0.45 \\
\hline Heptanal & 1.13 & 1.62 & 6.05 & $576.1^{* * *}$ & $1,176.5^{* * *}$ & $<0.01$ & 0.41 \\
\hline Octanal & 0.64 & 0.77 & 4.27 & $257.2^{* * *}$ & $642.2^{* * *}$ & $<0.01$ & 0.44 \\
\hline Oct-2-enal & - & 0.12 & 2.95 & - & $822.8^{* * *}$ & $<0.01$ & 0.32 \\
\hline Nonenal & 0.41 & 0.72 & 3.17 & $157.5^{* * *}$ & $294.2^{* * *}$ & $<0.01$ & 0.44 \\
\hline Decanal & 1.04 & 0.59 & 1.27 & 3.5 & $106.2^{* * *}$ & $<0.01$ & 0.21 \\
\hline$\Sigma$ Esters & 5.03 & 6.44 & 4.24 & 1.8 & $67.4^{* * *}$ & 0.01 & 0.87 \\
\hline Ethyl acetate & 2.08 & 0.84 & 4.17 & $10.3^{* *}$ & $465.8^{* * *}$ & 0.01 & 0.49 \\
\hline Ethyl lactate & - & - & 0.68 & - & - & - & 0.06 \\
\hline Ethyl butanoate & 4.45 & 6.42 & 0.60 & $62.6^{* * *}$ & $1,726.6^{* * *}$ & $<0.01$ & 0.44 \\
\hline Ethyl hexanoate & 3.86 & 5.25 & 0.76 & $41.2^{* * *}$ & $818.1^{* * *}$ & 0.63 & 0.49 \\
\hline Ethyl octanoate & 2.37 & 3.78 & 0.37 & $4.5^{*}$ & $398.1^{* * *}$ & $<0.01$ & 0.51 \\
\hline Ethyl decanoate & 1.13 & 2.73 & 0.45 & 14.9 & $239.5^{* * *}$ & 0.02 & 0.41 \\
\hline Ethyl dodecanoate & 0.56 & 0.99 & 0.38 & $10.3^{* *}$ & $166.8^{* * *}$ & $<0.01$ & 0.14 \\
\hline$\Sigma$ Fatty acids & 5.36 & 3.34 & 3.71 & $189.6^{* * *}$ & $5.7^{*}$ & 0.42 & 0.50 \\
\hline Acetic acid & 0.90 & - & 3.29 & - & - & 0.01 & 0.21 \\
\hline Butanoic acid & 3.91 & 1.27 & 1.21 & $368.3^{* * *}$ & 0.1 & $<0.01$ & 0.51 \\
\hline Hexanoic acid & 4.71 & 2.39 & 2.44 & $276.5^{* * *}$ & 0.1 & $<0.01$ & 0.51 \\
\hline Octanoic acid & 3.52 & 2.37 & 1.81 & $205.5^{* * *}$ & $22.1 * * *$ & 0.05 & 0.37 \\
\hline Nonanoic acid & 1.24 & 0.64 & 0.91 & $33.0 * * *$ & $8.1^{* *}$ & 0.19 & 0.29 \\
\hline Decanoic acid & 2.35 & 1.78 & 1.73 & $46.9 * * *$ & 0.2 & 0.01 & 0.33 \\
\hline$\Sigma$ Ketones & 1.78 & 1.55 & 4.21 & $397.4^{* * *}$ & $1,723.2^{* * *}$ & 0.34 & 0.21 \\
\hline Butan-2-one & 1.71 & 0.87 & 3.82 & $48.6^{* * *}$ & $788.8^{* * *}$ & 0.01 & 0.34 \\
\hline Pentan-2-one & - & - & 2.96 & - & - & - & 0.06 \\
\hline Heptan-2-one & 1.36 & 1.09 & 3.53 & $367.7^{* * *}$ & $1,819.1^{* * *}$ & 0.23 & 0.19 \\
\hline Heptan-3-one & 0.52 & 0.57 & 0.72 & $35.4^{* * *}$ & $37.8^{* * *}$ & $<0.01$ & 0.08 \\
\hline Nonan-2-one & 0.85 & 0.72 & 2.62 & $217.5^{* * *}$ & $878.1^{* * *}$ & $<0.01$ & 0.20 \\
\hline 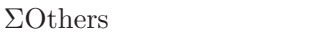 & 4.74 & 3.56 & 3.42 & $223.4^{* * *}$ & 2.3 & $<0.01$ & 0.31 \\
\hline Methylsulfonylmethane & 3.53 & 0.53 & 2.39 & $197.1^{* * *}$ & $113.8^{* * *}$ & $<0.01$ & 0.50 \\
\hline Methylthiomethane & 2.66 & 1.15 & 1.37 & $397.4^{* * *}$ & $7.6^{* *}$ & $<0.01$ & 0.26 \\
\hline Dihydrofuran-2(3H)-one & 0.56 & 1.21 & 0.55 & $36.9^{* * *}$ & $107.6^{* * *}$ & $<0.01$ & 0.19 \\
\hline 3-Methylphenol & 0.28 & 0.07 & 0.15 & $74.8 * * *$ & $13.4^{* * *}$ & $<0.01$ & 0.07 \\
\hline Toluene & 4.09 & 3.33 & 2.78 & $331.5^{* * *}$ & $70.2^{* * *}$ & 0.01 & 0.21 \\
\hline 6-Propyloxan-2-one & 0.66 & 0.40 & 0.60 & $8.4^{* *}$ & $9.2^{* *}$ & 0.01 & 0.20 \\
\hline Limonene & 1.21 & 0.78 & 0.64 & $26.2^{* * *}$ & 1.3 & $<0.01$ & 0.36 \\
\hline$\alpha$-Pinene & 1.01 & 0.66 & 0.50 & $32.3^{* * *}$ & 3.1 & $<0.01$ & 0.27 \\
\hline
\end{tabular}

${ }^{1} P$-values of the repeated factor cheese-making date.

${ }^{2} \mathrm{RMSE}=$ root mean squared error. Concentrations are expressed in micrograms equivalent to 4-methyl-pentan-2-one.

${ }^{*} P<0.05 .{ }^{* *} P<0.01$. ${ }^{* * *} P<0.001$. 
cheese. It is interesting to note that all the individual aldehydes, particularly hexanal, heptanal, octanal, and nonanal, were found in much greater concentrations in ricotta. These VOC may originate from $\beta$-oxidation of UFA or degradation of the AA (McSweeney and Sousa, 2000) and provide lemon, green, and other grassy notes in dairy products (Cornu et al., 2009). The pattern of these aldehydes in ricotta could be associated with spontaneous decomposition of hydroperoxides caused by heat (Grosch, 1982). Esters, on the other hand, were found in much lower amounts in ricotta than in the fresh cheese samples due to ethyl butanoate, ethyl hexanoate, ethyl octanoate, and ethyl decanoate almost disappearing and not compensated for by a corresponding increase in ethyl acetate (Table 3). It has been demonstrated that the ethyl esters can be produced by esterification of ethanol and acetic acid via the Fischer pathway catalyzed by heat (Hart, 1991). Furthermore, the higher amount of acetic acid in ricotta could be associated with the use of vinegar to catalyze the whey proteins. There were far greater relative amounts of all volatile ketones in the ricotta samples than in fresh cheese. There were no great differences in the concentrations of other VOC with the exception of a larger amount of methylsulfonylmethane (dimethyl sulfone) in ricotta and of dihydrofuran-2(3H)-one in fresh cheese. Any explanation of the differences between the 3 fresh products should take into account the conditions and the order of the 3 processing steps. The cream is separated from the whole evening milk after natural creaming with a mild change in acidity and temperature; the fresh cheese is obtained at the second step after moderate acidification and heating and enzymatic treatment; and, last, ricotta is obtained after intense acidification and, particularly, heating of the whey (Bergamaschi et al., 2016).

\section{Effects of Nutrient Depletion of Milk on VOC Profiles}

The progressive depletion of milk nutrients, especially fat and protein, during cheese and ricotta making affects VOC belonging to different chemical classes (Table 4) in the fluid by-products. Milk and whey had similar VOC profiles, whereas 2 new esters (ethyl lactate and butyl butanoate) appeared in very low quantities in scotta. Despite the uptake of VOC in fresh cheese (curd) and ricotta, the relative quantities of VOC increased from milk to whey and especially from whey to scotta. On a linear scale, the VOC concentration in scotta was more than double $(+136 \%)$ that in whey. The authors are unaware of any results in the scientific literature from comparisons of VOC in the various dairy fluids across the processing chain. Variations in the flavor attributes of whey from different types of cheese have also been investigated (Mahajan et al., 2004; Gallardo-Escamilla et al., 2005).

The largest chemical class in terms of relative quantity was the alcohols in whey and scotta, particularly 3-methylbutan-1-ol, 2-ethylhexanol, and octan-1-ol (especially in scotta). Pentan-1-ol, hexan-1-ol, and 1-octen-3-ol were present in much lower amounts in scotta than in whey. The relative concentrations of volatile aldehydes generally increased from milk to whey and from whey to scotta, whereas the majority of esters showed the opposite pattern (decreasing from milk to whey and from whey to scotta), with some exceptions (ethyl acetate and ethyl decanoate). Esters, especially those with few carbon atoms, are considered important aroma compounds in dairy products, giving fruity notes (Cornu et al., 2009; Villeneuve et al., 2013). Higher concentrations of these compounds in milk could be due to the positive relationship between some aroma compounds and proteins, which were investigated in a previous study (Farès et al., 1998).

The pattern displayed by VFA and ketones along the processing chain from milk to whey and scotta is similar to that observed for aldehydes; that is, an increase from milk to whey and from whey to scotta. Fatty acids with 4 or more carbon atoms can be formed through the action of native milk or bacterial lipases (McSweeney and Sousa, 2000; Chilliard et al., 2003), whereas ketones are listed as constituents of most dairy products (Fedele et al., 2005; Cornu et al., 2009; Bergamaschi et al., 2015a).

In the case of the "others" class, the opposite pattern (decreasing) was observed (similar to the majority of esters), with limonene disappearing in whey and scotta. The VOC in dairy products are generally in a lipophilic phase, so they can dissolve in the original fatty phase or bind to the proteins during processing (Mariaca and Bosset, 1997). Moreover, adsorption and desorption of these compounds can be affected by the physical parameters of the food matrix. For example, accumulation of some volatile compounds in dairy products with a low $\mathrm{pH}$ (higher acidity; e.g., scotta in this study) has been reported by Imhof and Bosset (1994). On the basis of these sources of variation, is it important to optimize an extraction procedure per each dairy product.

\section{Effects of Ripening on Cheese VOC}

Ripening of Malga cheese caused an enormous change in the VOC profiles, with ripening periods of 6 mo and 12 mo increasing relative abundances to 22 and 31 times the linear concentrations $(\mu \mathrm{g} / \mathrm{kg})$ in fresh cheese, respectively (Table 5). In particular, ripened cheese had 5 alcohols with high concentrations (butan-1-ol, butan-2-ol, pentan-2-ol, hexan-2-ol, and heptan-2-ol) that were not detectable in fresh cheese; it also had 1 
more aldehyde (3-methylbutanal), 2 more esters (ethyl increased dramatically during ripening with the exceplactate and ethyl butanoate), and 1 more fatty acid tion of methylsulfonylmethane (dimethyl sulfone; Table (acetic acid) than fresh cheese. The concentration of 5). On the other hand, 2 VOC identified in fresh cheese all the VOC present in both fresh and ripened cheeses were no longer detectable in ripened cheeses [nonenal

Table 4. Comparison of volatile organic compounds (VOC) of vat milk and derived liquid by-products expressed as natural logarithm of concentration $(\mu \mathrm{g} / \mathrm{kg})$

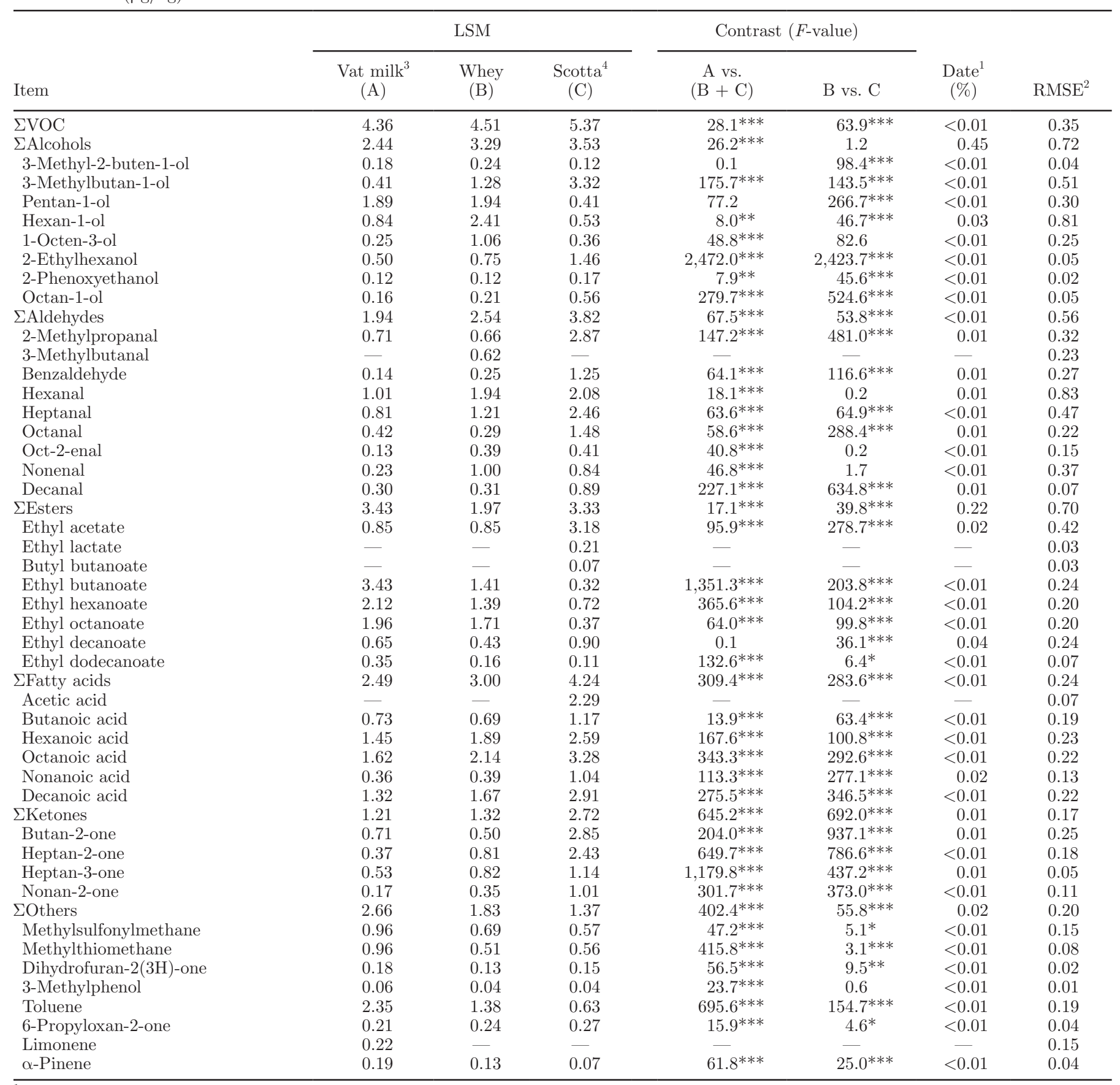

${ }^{1} P$-values of the repeated factor cheese-making date.

${ }^{2} \mathrm{RMSE}=$ root mean squared error. The concentrations are expressed in micrograms equivalent to 4-methyl-pentan-2-one.

${ }^{3}$ Obtained by mixing the evening skim milk with the morning whole milk in equal parts.

${ }^{4} \mathrm{Scotta}=$ residual liquid.

${ }^{*} P<0.05 .{ }^{* *} P<0.01$. ${ }^{* * *} P<0.001$. 
Table 5. Effect of ripening of cheese for 6 or 12 mo on volatile organic compounds (VOC) expressed as natural logarithm of concentration ( $\mu \mathrm{g} /$ $\mathrm{kg}$ ) of curd (fresh cheese) and ripened cheese

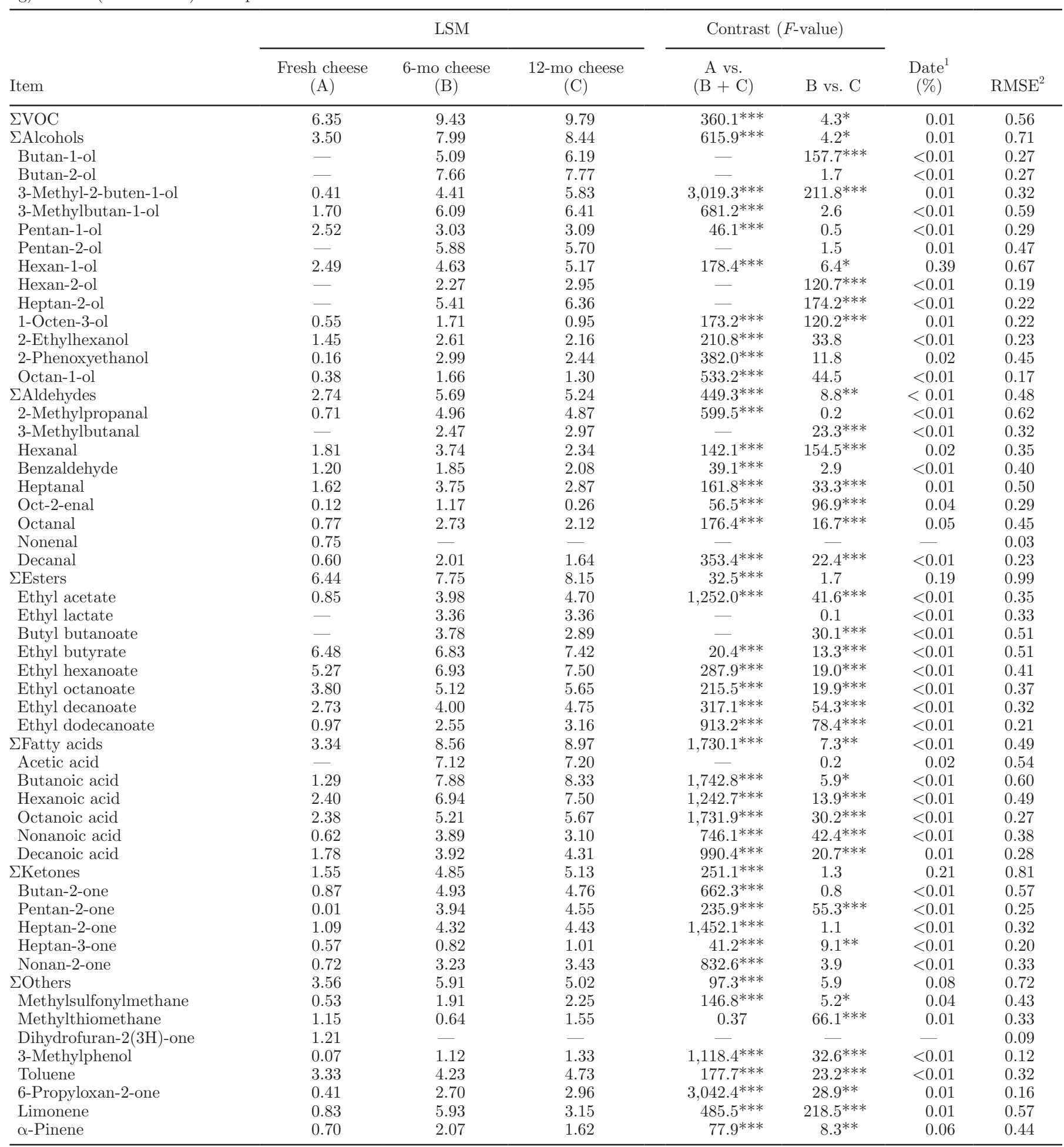

${ }^{1} P$-values of the repeated factor cheese-making date.

${ }^{2} \mathrm{RMSE}=$ root mean squared error. Concentrations are expressed in micrograms equivalent to 4-methyl-pentan-2-one.

${ }^{*} P<0.05 .{ }^{* *} P<0.01$. ${ }^{* * *} P<0.001$. 


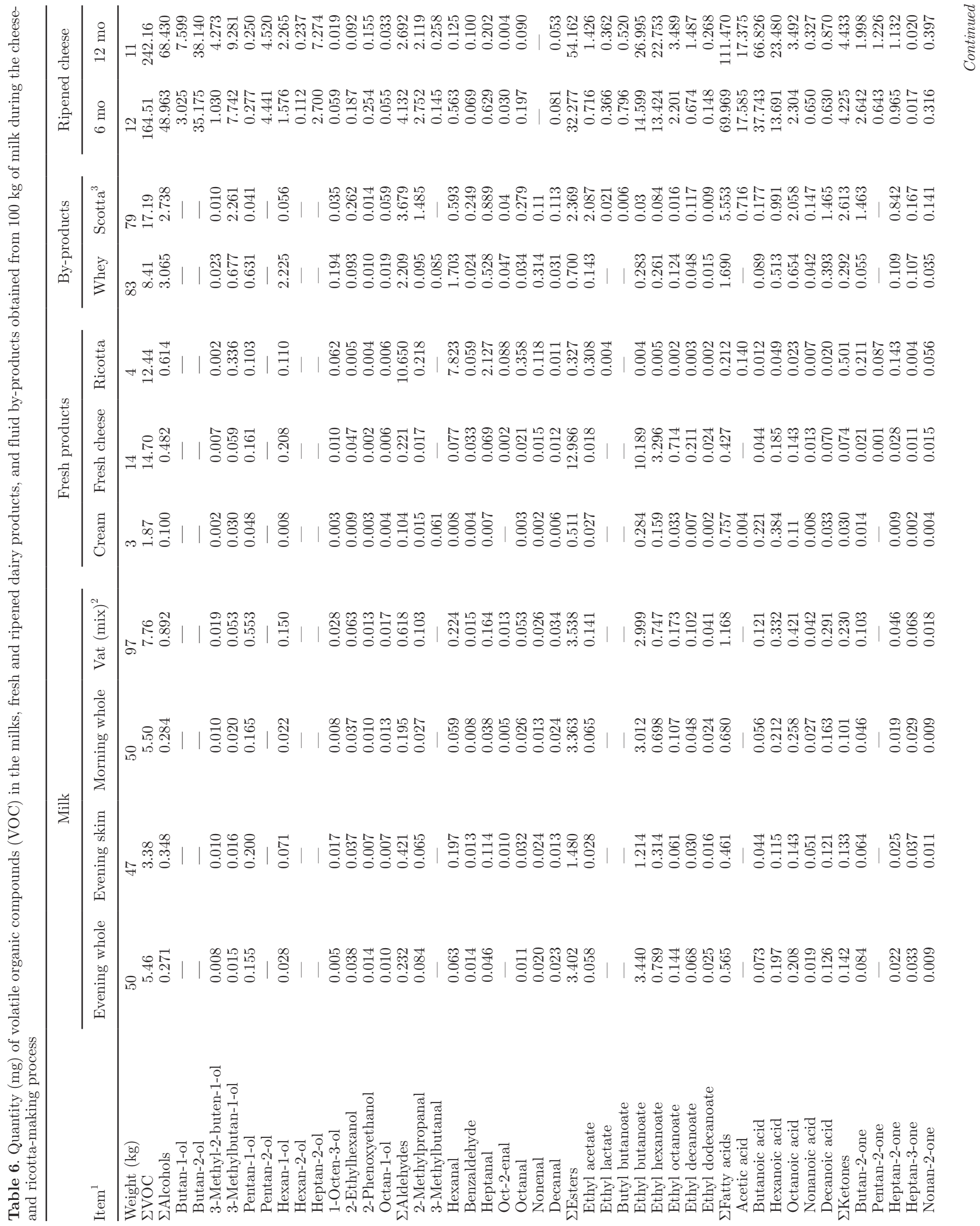


and dihydrofuran-2(3H)-one]. Overall, during the first 6 mo of ripening, esters increased their linear concentration almost 4 times, ketones and other compounds 10 times, aldehydes 20 times, alcohols 90 times, and fatty acids almost 200 times.

The milk constituents (fat and protein) retained in the curd can be transformed into cheese flavor compounds and aroma precursors (Smit et al., 2005). The presence of microorganisms in the fresh cheese (curd) and the activity of milk native enzymes, especially proteases and lipases, could be mainly responsible for these variations. In a review, Gatti et al. (2014) reported that more than one third of cheese proteins are hydrolyzed by synergic activity of plasmin, cathepsin, microbial proteases and peptidases during long cheese ripening periods.

Comparing the samples of cheeses ripened for 6 and 12 mo, we found a further increase in the relative quantities of VOC in the second 6 mo of ripening to be smaller than in the first 6 mo of ripening. There was also large variability among and within chemical classes of VOC (Table 5). The sum of the 13 volatile alcohols identified increased from 6 to 12 mo of ripening, which was due to an increase in 5 compounds of this class (particularly butan-1-ol, 3-methyl-2-buten-1-ol, and heptan-2-ol), whereas 1 compound decreased (1-octen3 -ol) and 7 showed minor variations. The primary alcohols may originate from the corresponding aldehydes derived from fatty acid and AA metabolism, whereas the secondary alcohols are produced mainly through reduction of methyl ketones (McSweeney and Sousa, 2000). These compounds are responsible for alcoholic and floral notes (Cornu et al., 2009). Bovolenta et al. (2014) found several primary and secondary alcohols in the VOC profile of Montasio cheese ripened for $60 \mathrm{~d}$. The sum of the 9 aldehydes decreased with advanced ripening because although 1 of them increased (3-methylbutanal), 5 decreased (especially hexanal, heptanal, octanal, and oct-2-enal). Aldehydes may derive from AA during ripening (Strecker degradation) and provide malty and herbaceous flavors (McSweeney and Sousa, 2000; Cornu et al., 2009). In some cheeses, they are thought to be the most important flavor compounds (Curioni and Bosset, 2002). The sum of the 8 esters differed little in 6- and 12-mo cheeses even though almost all of them increased; this was due to a large decrease in butyl butanoate and no significant variation in ethyl lactate. The sum of fatty acids increased, as did 4 of the 6 compounds of this class, whereas acetic acid remained almost unchanged and only nonanoic acid decreased. The 3 main pathways in fatty acids formation are lipolysis, proteolysis, and lactose fermentation (Curioni and Bosset, 2002). During cheese ripening, depending on processing, microflora, and ripening 
conditions, one of these pathways will be dominant (McSweeney and Sousa, 2000). Production of butanoic, hexanoic, octanoic, and decanoic acid could be associated with activity of lipases and esterases, whereas the formation of acetic acid may be associated with carbohydrate metabolism during ripening. There were no great variations in the 5 ketones as only pentan2-one and heptan-3-one increased. The biochemistry of cheese ripening has been extensively studied (Fox et al., 2004). Biochemical changes involve the metabolism of residual fat, protein, and lactose, which may yield precursors for the formation of aroma compounds (McSweeney and Sousa, 2000; Fox et al., 2004). The other 8 VOC increased with the exception of $\alpha$-pinene and, especially, limonene, which decreased. The variation in terpenes could be due to possible biotransformation of these compounds during ripening (de Carvalho and da Fonseca, 2006). Furthermore, Cornu et al. (2005) reported that terpenes can influence the dynamics or the biochemical activities of the microbial ecosystem during cheese manufacture and ripening. Nevertheless, these mechanisms need further investigation.

\section{Evolution of VOC Across the Cheese- and Ricotta-Making Processes}

Tentative quantification of VOC across the cheeseand ricotta-making chain expressed per 100 kilograms of processed milk is summarized in Table 6 and Figure 1. The results were obtained using SPME/GC-MS, which generates semiquantitative VOC data (Pawliszyn, 2000). Weights were obtained of the 11 products and by-products controlled and sampled during the 7 experimental cheese- and ricotta-making sessions that took place from June to September, as described in a previous study (Bergamaschi et al., 2016). The relative quantities of VOC were estimated by multiplying the weight of the product obtained from 100 kilograms of processed milk by the VOC concentrations from Tables $2,3,4$, and 5 , linearly transformed to micrograms per kilogram equivalent to the internal standard. As shown in Figures 1 and 2a-c, overnight natural skimming did not cause appreciable variations in the relative quantity of VOC (their sum in cream and skim milk is about $4 \%$ lower than in the initial whole milk). The transfer, mixing, and heating of evening skim milk and morning whole milk in the cheese vat caused a small decrease in the relative quantity of VOC $(-13 \%)$. Conversely, at the end of cheese making the quantity of VOC in the whey was $8 \%$ more than in the vat milk before the addition of the starter and rennet and the quantity of $\mathrm{VOC}$ in the fresh cheese was almost twice that in the vat milk. Therefore, cheese making (combining the whey and fresh cheese) caused a large increase in the overall quantity of VOC $(+198 \%)$. As for the ricottamaking process, Figure 1 shows that the residual scotta had about twice the quantity of VOC than the whey before heating and acidification, whereas ricotta contained about 1.5 times the initial quantity of VOC in whey. The sum of scotta and ricotta greatly increased the relative quantity of VOC compared with the whey $(+252 \%)$. The third step, cheese ripening, caused a dramatic change in the overall quantity of VOC, which increased 11-fold $(+1,019 \%)$ after 6 mo and 16-fold $(+1,548 \%)$ after 12 mo of ripening.

It is beyond the scope of this study to analyze in detail the quantitative balance of each VOC over the entire process, but the data in Table 6 clearly show the complex evolution of VOC in milk and milk products. From this it is possible to estimate the partition of each substance in different products, the disappearance, and especially the appearance of the different VOC as a result of the activity of milk native enzymes, microbiological activity, heat treatments, acidification, and physical treatments as well as the interactions among these factors.

The results clearly revealed a partition of VOC of evening whole milk between skim milk and cream. More precisely, 60 to $65 \%$ of the relative quantities of 2-phenoxyethanol, octan-1-ol, 2-methylpropanal, nonenal, decanal, ethyl acetate, octanoic acid, methylthiomethane, toluene, and $\alpha$-pinene in the evening whole milk was transferred to the skim milk, whereas 30 to $35 \%$ of the concentrations of these VOC were transferred to the cream. It is well known that the fat content of dairy products has an effect on volatile compounds and consequently on flavor release (Smit et al., 2005; Cadwallader and Singh, 2009). The presence of fat in the food matrix can solubilize hydrophobic compounds, although only a small proportion of these volatile molecules find their way into the headspace, thereby increasing the sensory threshold and influencing flavor release (Kim et al., 2011; Shepard et al., 2013). Compared with whole milk and skim milk, cream has a higher concentration of the flavor-active compound butanoic acid, which is mainly derived from lipolysis (Curioni and Bosset, 2002). As mentioned earlier, 3-methyl-2-buten-1-ol, 3-methylbutan-1-ol, heptan-2-one, nonan-2-one, and dihydrofuran-2(3H)-one seem to be quite constant over the creaming process, especially between evening whole milk and skim milk (Table 6). We found a quantitative transfer of VOC from vat milk to curd (fresh cheese) and whey. Approximately 25 to $30 \%$ of 1 -octen-3-ol, 2-phenoxyethanol, octan-1-ol, and butanoic acid was retained in the fresh cheese, whereas 70 to $75 \%$ was lost in the whey (Table 6). Another interesting aspect of cheese production is the evolution of the VOC profile during ricotta making. In general, we found greater 
BY-PRODUCTS: $\quad$ MILK: PRODUCTS:

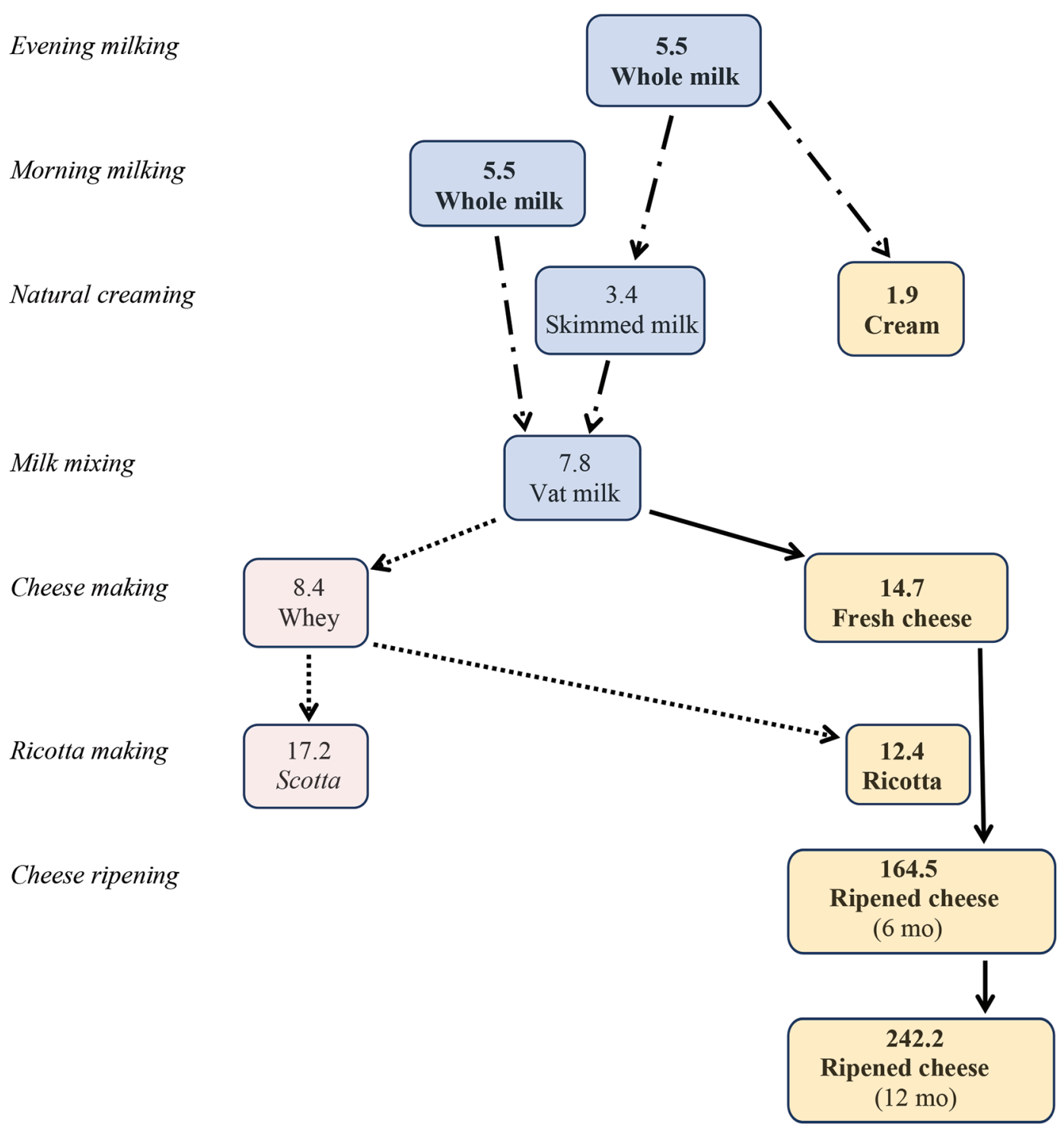

Figure 1. Flow of average content (mg) of volatile organic compounds in the headspace of different dairy products and by-products obtained from creaming, cheese making, and ricotta making. Color version available online.

quantities of fatty acids, esters, and ketones in scotta than in whey and ricotta, and of these chemical families the most significant increases were in butan-2-one, which was 29 times higher in scotta than in whey. As discussed previously, these differences in proportions could be due to the heat treatment before coagulation or lactic acid fermentation (Shepard et al., 2013). In addition, ricotta had higher concentrations of hexanal, octanal, and decanal derived from $\beta$-oxidation of UFA (McSweeney and Sousa, 2000).

\section{CONCLUSIONS}

We carried out the first investigation of the VOC of 11 dairy products (whole evening milk, skim milk, whole morning milk mixed in the vat milk, cream, curd, whey, ricotta, scotta, and 6 mo- and 12 mo-ripened cheeses) analyzed by SPME/GC-MS. In this experiment, carried out on dairy products from an Alpine pasture, we identified molecules belonging to different chemical families: alcohols, aldehydes, esters, free fatty 
a) Milks

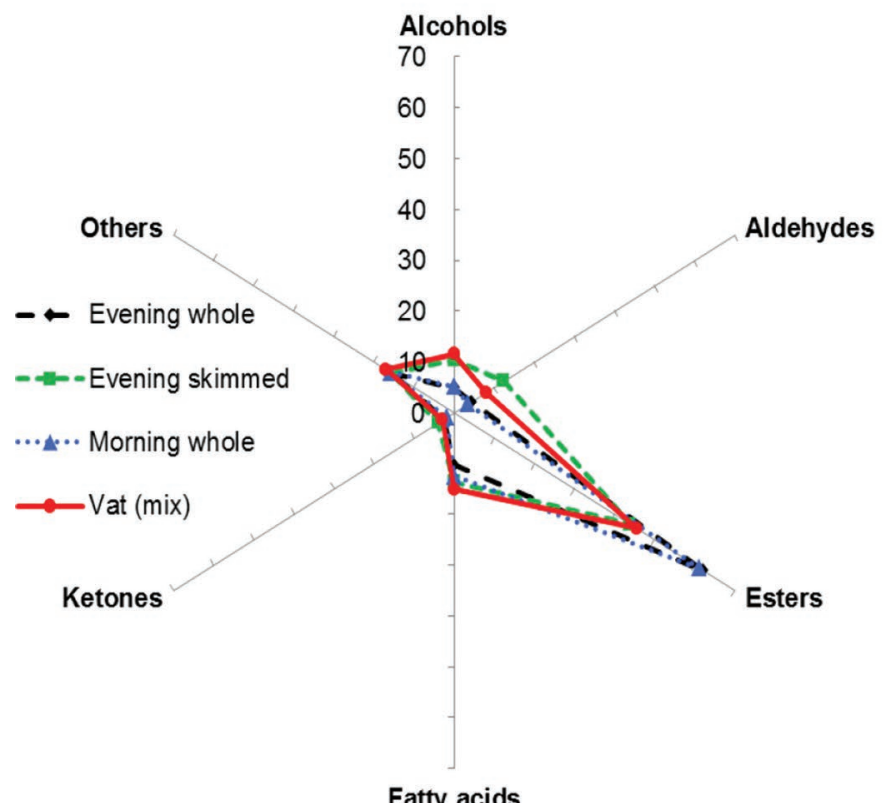

Fatty acids

\section{b) Cheese making}

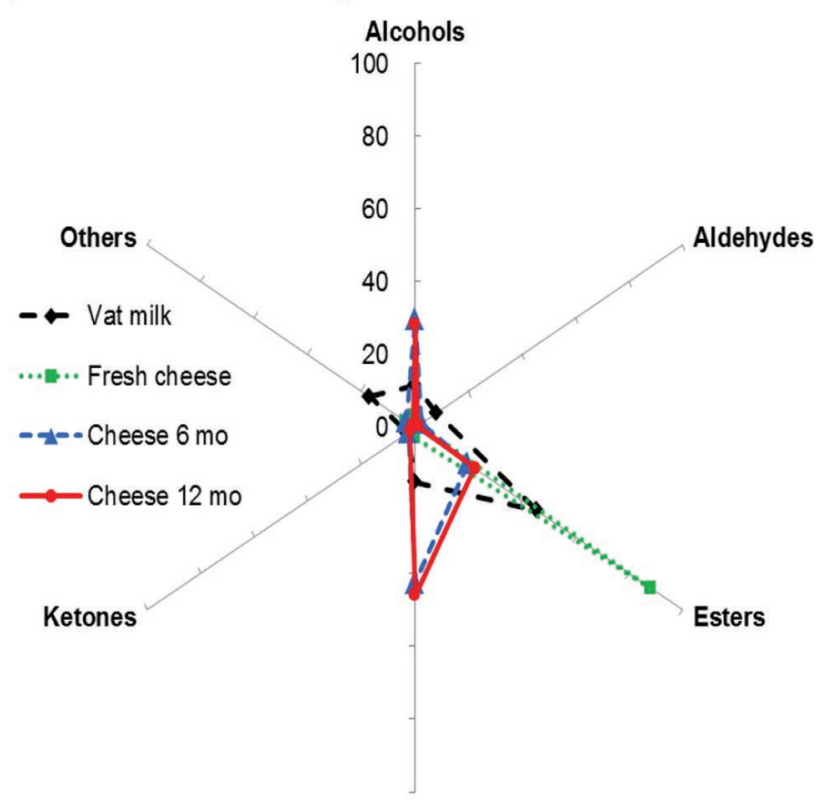

Fatty acids

c) Ricotta making

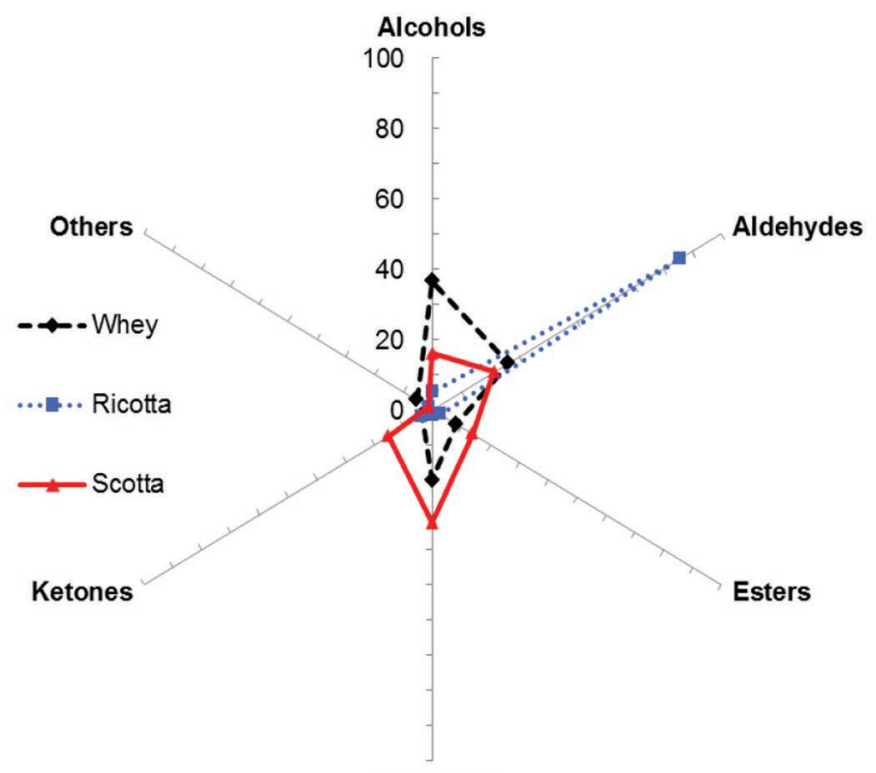

Fatty acids

Figure 2. Average proportion (\%) of the main volatile organic compound families in the headspace of different dairy products and byproducts obtained from (a) creaming (milks), (b) cheese making, and (c) ricotta making. Color version available online.

acids, ketones, lactones, sulfurs, terpenes, phenols, and benzenes. The evolution of VOC depends on specific technological aspects of the cheese- and ricotta-making processes, such as natural skimming, temperature, and ripening period. We conclude that distinctive VOC can be used as markers of product and process.

\section{ACKNOWLEDGMENTS}

The authors thank the Autonomous Province of Trento (Trento, Italy) for financial support and Flavia Gasperi, Franco Biasioli, Emanuela Betta, and Eugenio Aprea (Department of Food Quality and Nutrition, 
Research and Innovation Centre, Fondazione Edmund Mach, San Michele all' Adige, Trento, Italy) for solidphase microextraction GC-MS analysis.

\section{REFERENCES}

Agabriel, C., B. Martin, C. Sibra, J. C. Bonnefoy, M. C. Montel, R. Didienne, and S. Hulind. 2004. Effect of dairy production system on the sensory characteristics of Cantal cheeses: A plant-scale study. Anim. Res. 53:221-234.

Badings, H. T. 1991. Milk. Pages 91-106 in Volatile Compounds in Food and Beverages. H. Maarse, ed. Marcel Dekker Inc., New York, NY.

Barrefors, P., K. Granelli, L. Appelquist, and L. Bjoerck. 1995. Chemical characterization of raw milk samples with and without oxidative off flavor. J. Dairy Sci. 78:2691-2699.

Bergamaschi, M., E. Aprea, E. Betta, F. Biasioli, C. Cipolat-Gotet, A. Cecchinato, G. Bittante, and F. Gasperi. 2015a. Effects of the dairy system, herd and individual cow characteristics on the volatile organic compound profile of ripened model cheeses. J. Dairy Sci. 98:2183-2196.

Bergamaschi, M., F. Biasioli, A. Cecchinato, C. Cipolat-Gotet, A. Cornu, F. Gasperi, B. Martin, and G. Bittante. 2015b. PTR-ToF-MS: A high-throughput and innovative method to study the influence of dairy system and cow characteristics on the volatile compound fingerprint of cheeses. J. Dairy Sci. 98:8414-8427.

Bergamaschi, M., and G. Bittante. 2017. Detailed fatty acid profile of milk, cheese, ricotta and by products, from cows grazing summer highland pastures. J. Dairy Res. 84:329-338.

Bergamaschi, M., C. Cipolat-Gotet, G. Stocco, C. Valorz, I. Bazzoli, E. Sturaro, M. Ramanzin, and G. Bittante. 2016. Cheese-making in highland pastures: Milk technological properties, cream, cheese and ricotta yields, milk nutrients recovery, and products composition. J. Dairy Sci. 99:9631-9646.

Bitman, J., A. Lefcourt, D. L. Wood, and B. Stroud. 1984. Circadian and ultradian temperature rhythms of lactating dairy cows. J. Dairy Sci. 67:1014-1023.

Bovolenta, S., A. Romanzin, M. Corazzin, M. Spanghero, E. Aprea, F. Gasperi, and E. Piasentier. 2014. Volatile compounds and sensory properties of Montasio cheese made from the milk of Simmental cows grazing on alpine pastures. J. Dairy Sci. 97:7373-7385.

Cadwallader, K. R., and T. K. Singh. 2009. Flavors and off-flavors in milk and dairy products. Adv. Dairy Chem. 3:631-690.

Caplan, Z., C. Melilli, and D. M. Barbano. 2013. Gravity separation of fat, somatic cells, and bacteria in raw and pasteurized milks. J. Dairy Sci. 96:2011-2019.

Capuano, E., R. Gravink, R. Boerrigter-Eenling, and S. M. van Ruth. 2015. Fatty acid and triglycerides profiling of retail organic, conventional and pasture milk: Implications for health and authenticity. Int. Dairy J. 42:58-63.

Carpino, S., S. Mallia, S. La Terra, C. Melilli, G. Licitra, T. E. Acree, D. M. Barbano, and P. J. Van Soest. 2004. Composition and aroma compounds of Ragusano cheese: Native pasture and total mixed rations. J. Dairy Sci. 87:816-830.

Chilliard, Y., A. Ferlay, J. Rouel, and G. Lamberet. 2003. A review of nutritional and physiological factors affecting goat milk lipid synthesis and lipolysis. J. Dairy Sci. 86:1751-1770.

Collin, S., M. Osman, S. Delcambre, A. I. El-Zayat, and J. P. Dufourt. 1993. Investigation of volatile flavor compounds in fresh and ripened Domiati cheeses. J. Agric. Food Chem. 41:1659-1663.

Coppa, M., I. Verdier-Metz, A. Ferlay, P. Pradel, R. Didienne, A. Farruggia, M. C. Montel, and B. Martin. 2011. Effect of different grazing systems on upland pastures compared with hay diet on cheese sensory properties evaluated at different ripening times. Int. Dairy J. 21:815-822.

Cornu, A., N. Kondjoyan, B. Martin, I. Verdier-Metz, P. Pradel, J. L. Berdague, and J. B. Coulon. 2005. Terpene profiles in Cantal and Saint-Nectaire-type cheese made from raw or pasteurised milk. J. Sci. Food Agric. 85:2040-2046.
Cornu, A., N. Rabiau, N. Kondjoyan, I. Verdier-Metz, P. Pradel, P. Tournayre, J. L. Berdagué, and B. Martin. 2009. Odour-active compound profiles in Cantal-type cheese: Effect of cow diet, milk pasteurization and cheese ripening. Int. Dairy J. 19:588-594.

Coulon, J. B., A. Delacroix-Buchet, B. Martin, and A. Pirisi. 2004. Relationships between ruminant management and sensory characteristics of cheeses: A review. Lait 84:221-241.

Curioni, P. M. G., and J. O. Bosset. 2002. Key odorants in various cheese types as determined by gas chromatography-olfactometry. Int. Dairy J. 12:959-984.

Das, R., L. Sailo, N. Verma, P. Bharti, and J. Saikia. 2016. Impact of heat stress on health and performance of dairy animals: A review. Vet. World 9:260-268.

de Carvalho, C. C. C. R., and M. M. R. Da Fonseca. 2006. Biotransformation of terpenes. Biotechnol. Adv. 24:134-142.

Farès, K., P. Landy, R. Guilard, and A. Voilley. 1998. Physico-chemical interactions between aroma compounds and milk proteins: Effect of water and protein modification. J. Dairy Sci. 81:82-91.

Fedele, V., R. Rubino, S. Claps, L. Sepe, and G. Morone. 2005. Seasonal evolution of volatile compounds content and aromatic profile in milk and cheese from grazing goat. Small Rumin. Res. 59:273-279.

Fox, P. F., P. L. H. McSweeney, T. M. Cogan, and T. P. Guinee. 2004 Cheese: Chemistry, Physics and Microbiology. Vol. 1. General Aspects. 3rd ed. Elsevier/Academic Press, London, United Kingdom.

Gallardo-Escamilla, F. J., A. L. Kelly, and C. M. Delahunty. 2005. Sensory characteristics and related flavor compound profiles of different types of whey. J. Dairy Sci. 88:2689-2699.

Gatti, M., B. Bottari, C. Lazzi, E. Neviani, and G. Mucchetti. 2014. Invited review: Microbial evolution in raw-milk, long-ripened cheeses produced using undefined natural whey starters. J. Dairy Sci. 97:573-591.

Giaccone, D., A. Revello-Chion, L. Galassi, P. Bianchi, G. Battelli, M. Coppa, E. Tabacco, and G. Borreani. 2016. Effect of milk thermisation and farming system on cheese sensory profile and fatty acid composition. Int. Dairy J. 59:10-19.

Gobbetti, M., P. F. Fox, and L. Stepaniak. 1996. Esterolytic and lipolytic activities of mesophilic and thermophilic lactobacilli. Ital. J. Food Sci. 8:127-137.

Grosch, W. 1982. Lipid degradation products and flavour. Pages 325385 in Food Flavours. Part A. Introduction. I. D. Morton and A. J. Macleod, ed. Elsevier Scientific, Amsterdam, the Netherlands.

Harmer, S. L. 2009. The circadian system in higher plants. Annu. Rev. Plant Biol. 60:357-377.

Hart, H. 1991. Organic Chemistry: A Short Course. 8th ed. Houghton Mifflin, Boston, MA.

Imhof, R., and J. O. Bosset. 1994. Relationships between micro-organisms and formation of aroma compounds in fermented dairy products. Z. Lebensm. Unters. Forsch. 198:267-276.

Kim, M. K., S. L. Drake, and M. A. Drake. 2011. Evaluation of key flavor compounds in reduced- and full-fat Cheddar cheeses using sensory studies on model systems. J. Sens. Stud. 26:278-290.

Liaw, I. W., R. E. Miracle, S. M. Jervis, M. A. D. Listiyani, and M. A. Drake. 2011. Comparison of the flavor chemistry and flavor stability of Mozzarella and Cheddar wheys. J. Food Sci. 76:C1188C1194.

Mahajan, S. S., L. Goddick, and M. C. Qian. 2004. Aroma compounds in sweet whey powder. J. Dairy Sci. 87:4057-4063.

Mariaca, R., and J. O. Bosset. 1997. Instrumental analysis of volatile (flavour) compounds in milk and dairy products. Lait 77:13-40.

Marsili, R. T. 1999. SPME-MS-MVA as an electronic nose for the study of off-flavors in milk. J. Agric. Food Chem. 47:648-654.

Martin, B., D. Pomiès, P. Pradel, I. Verdier-Metz, and B. Rémond. 2009. Yield and sensory properties of cheese made with milk from Holstein or Montbéliarde cows milked twice or once daily. J. Dairy Sci. 92:4730-4737.

Martin, B., I. Verdier-Metz, S. Buchin, C. Hurtaud, and J. B. Coulon. 2005. How does the nature of forages and pastures diversity influence the sensory quality of dairy livestock products? J. Anim. Sci. $81: 205-212$.

McLafferty, F. W. 2006. Wiley Registry of Mass Spectral Data. 8th ed. Wiley, Hoboken, NJ. 
McSweeney, P. L. H., and M. J. Sousa. 2000. Biochemical pathways for the production of flavor compounds in cheeses during ripening: A review. Lait 80:293-324.

Pawliszyn, J. 2000. Theory of solid-phase microextraction. J. Chromatogr. Sci. 38:270-278.

Peterson, D. G., and G. A. Reineccius. 2003. Characterization of the volatile compounds that constitute fresh sweet cream butter aroma. Flavour Fragrance J. 18:215-220.

Shepard, L., R. E. Miracle, P. Leksrisompong, and M. A. Drake. 2013. Relating sensory and chemical properties of sour cream to consumer acceptance. J. Dairy Sci. 96:5435-5454.

Smit, G., B. Smit, and W. Engels. 2005. Flavor formation by lactic acid bacteria and biochemical flavor profiling of cheese products. FEMS Microbiol. Rev. 29:591-610.

Sturaro, E., E. Marchiori, G. Cocca, M. Penasa, M. Ramanzin, and G. Bittante. 2013a. Dairy systems in mountainous areas: Farm animal biodiversity, milk production and destination, and land use. Livest. Sci. 58:157-168.

Sturaro, E., M. Thiene, G. Cocca, M. Mrad, T. Tempesta, and M. Ramanzin. 2013b. Factors influencing summer farms management in the Alps. Ital. J. Anim. Sci. 12:153-161.

Timmons, J. S., W. P. Weiss, D. L. Palmquist, and W. J. Harper. 2001. Relationships among dietary roasted soybeans, milk com- ponents, and spontaneous oxidized flavor of milk. J. Dairy Sci. $84: 2440-2449$.

Tunick, M. H. 2014. Analyzing volatile compounds in dairy products. J. Sci. Food Agric. 94:1701-1705.

Tunick, M. H., M. Paul, E. R. Ingham, H. J. Karreman, and D. L. Van Hekken. 2015. Differences in milk characteristics between a cow herd transitioning to organic versus milk from a conventional dairy herd. Int. J. Dairy Technol. 68:511-518.

Villeneuve, M. P., Y. Lebeuf, R. Gervais, G. F. Tremblay, J. C. Vuillemard, J. Fortin, and P. Y. Chouinard. 2013. Milk volatile organic compounds and fatty acid profile in cows fed timothy as hay, pasture, or silage. J. Dairy Sci. 96:7181-7194.

Zendri, F., M. Ramanzin, G. Bittante, and E. Sturaro. 2016. Transhumance of dairy cows to highland summer pastures interacts with breed to influence body condition, milk yield and quality. Ital. J. Anim. Sci. 15:481-491.

Zendri, F., M. Ramanzin, C. Cipolat-Gotet, and E. Sturaro. 2017. Variation of milk coagulation properties, cheese yield, and nutrients recovery in curd of cows of different breeds before, during and after transhumance to highland summer pastures. J. Dairy Res. $84: 39-48$. 